\title{
Особенности смысловых процессов и явлений в командном взаимодействии
}

\section{Евгений А. Проненко*, Мария В. Буняева}

Южный федеральный университет, г. Ростов-на-Дону, Российская Федерация

*E-mail: pronenko@sfedu.ru

\begin{abstract}
Аннотация
Введение. Целью статьи является рассмотрение смысловых процессов и явлений в команде, успешность протекания которых может рассматриваться как условие развития команАного взаимодействия. Наравне с социально-психологическими аспектами взаимоотношений в команде и аспектами управления важно изучить глубинные смысловые аспекты команАного взаимодействия. Исследование направ^ено на изучение условий протекания смысловых процессов в команде и фракторов, способствующих или препятствующих им. Новизна исслеАования заключается в Аетальном рассмотрении смысловых аспектов командного взаимодействия, ранее этот аспект бы^ слабо отражен в исслеАовании команА.
\end{abstract}

Теоретическое обоснование. Методология исследования основана на теории самоорганизации совместной мыслительной Аеятельности (А. К. Белоусова), позволяющей прослеАить смысловую Аинамику в рамках команАного взаимоАействия, а также положениях отечественной психологии смысла (А. А. ^еонтьев, И. В. Абакумова и $А$ р.).

Результаты и их обсужаение. Рассмотрены особенности процесса смыслопереАачи в команАе, посреАством которого фрормируются общие новообразования психологические ситуации, смыслы, мотивы, цели, оценки, которые, в свою очередь,

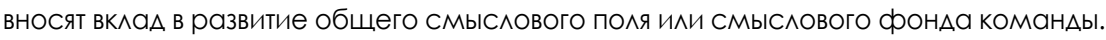
Обозначена важность установления межАу участниками команАы смысловой коммуникации. Осознанное общее понимание участниками команды того, что и как они Аелают, способствует как гармоничным межличностным отношениям, так и эфрфрективной коммуникации, необхолимой Аля успешной работы. Технологией, обеспечивающей смысловую коммуникацию, является смысловой Аиалог, который способствует изменениям ценностно-смысловой сореры участников команАы. Аостижение смыслового резонанса способствует установлению смысловой коммуникации межАу участниками команАы, а смысловой Аиссонанс выступает барьером Аля этого. Рассмотрена смысловая сторона сп^оченности команАы сложного явления, влияющего на многие командные процессы. Результаты исслеАОвания могут быть использованы А^я Аальнейшего изучения смысловых аспектов команАного взаимодействия, в практике командообразования; они преАставляют 
интерес Аля специалистов, исслеАующих команды или проводящих с ними практическую психологическую работу.

\section{Ключевые слова}

команда, совместная мыслительная Аеятельность, смыслопередача, общий Смысловой фонА, смысловая коммуникация, смысловой резонанс, смысловой Аиссонанс, сплоченность команды, общее понимание, совместное ^илерство

\section{Основные положения}

- оАНОЙ Из основ КоманАного взаимодействия является общее преАставление Участников о своей Аеятельности: ОНо скАаАЫвается из общих психологических новообразований, фрормирующихся в процессе совместной мыслительной Аеятельности; - $\Delta \wedge я$ повышения результативности Аеятельности в команде необхолимо подАерживать высокое качество коммуникации межАу участниками - такое качество может быть обеспечено развитием смысловых аспектов коммуникации с помощью непосредственного диалога межАу членами команды;

- сплоченность команаы в контексте рассмотрения смыслового аспекта команАного взаимодействия преАСтавляет собой готовность Участников К Смысловой коммуникации; сплоченность яв^яется важным условием поААержки совместного АиАерства в команде.

\section{Для цитирования}

Проненко Е. А., Буняева М. В. Особенности смысловых процессов и явлений в командном взаимодействии // Российский психологический журнал. 2019. Т. 16, № 1. C. 32-51. DOI: 10.21702/rpj.2019.1.2

Материалы статьи получены 22.12.2018

UDC 159.99

DOI: $10.21702 / r p j .2019 .1 .2$

\section{Characteristics of Meaning Processes and Phenomena in Team Interaction}

\section{Evgeny A. Pronenko*, Maria V. Bunyaeva}

Southern Federal University, Rostov-on-Don, Russian Federation

* Corresponding author: pronenko@sfedu.ru

\section{Abstract}

Introduction. Along with the socio-psychological characteristics of team interaction and management issues, innermost meaning aspects of team interaction merit special 
attention. The successful realization of meaning processes and phenomena determines the development of team interaction in teams. At present, little is known about meaning aspects of team interaction. This study investigates the conditions of meaning processes in teams and factors contributing to and hindering them.

Theoretical Basis. The theory of self-organization of joint mental activity (A. K. Belousova) as a framework for revealing meaning dynamics in team interaction and also fundamental propositions of the psychology of meaning developed by Russian researchers (D. A. Leontiev, I. V. Abakumova, etc.) provided methodological foundations for the present study.

Results and Discussion. The authors considered the process of meaning transmission which generates common new formations in teams including psychological situations, meanings, motives, goals, and assessments. In turn, these new formations contribute to the development of the common meaning field or meaning fund in teams. Meaning communication among team members is extremely important. Team members' perceived shared understanding of what they do and how they do promotes both harmonious interpersonal relationships and effective communication which is important for successful work. Meaning dialogue is a technology that provides meaning communication and changes in team members' value-meaning sphere. Meaning resonance contributes to meaning communication among team members; meaning dissonance impedes it. The meaning aspect of team cohesion is a complex phenomenon that affects many team processes. The results of the study can be used in a further study of meaning aspects of team interaction in the practice of team formation. The findings are of interest to the specialists engaged in studying teams and psychology practitioners working with teams.

\section{Keywords}

team, joint mental activity, meaning transmission, common meaning fund, meaning communication, meaning resonance, meaning dissonance, team cohesion, shared understanding, shared leadership

\section{Highlights}

- Team members' common representation of their activities is a foundation for team interaction; common new formations that are formed during joint mental activity form the basis for such a representation.

- High quality communication among team members can help improve performance of team activities; developing meaning aspects of communication through direct dialogue among team members may provide such a high quality communication.

- From the standpoint of meaning aspects of team interaction, team cohesion represent participants' willingness for meaning communication; team cohesion is an important condition for shared leadership in teams. 


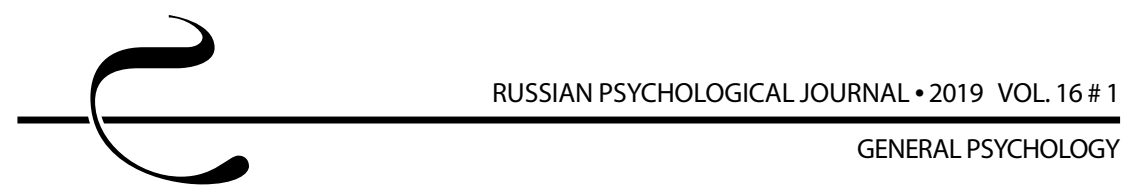

\section{For citation}

Pronenko E. A., Bunyaeva M. V. Characteristics of Meaning Processes and Phenomena in Team Interaction. Rossiiskii psikhologicheskii zhurnal - Russian Psychological Journal, 2019, V. 16, no. 1, pp. 32-51 (in Russian). DOI: 10.21702/rpj.2019.1.2

Original manuscript received 22.12.2018

\section{Введение}

Командная форма взаимодействия людей для решения рабочих или учебных задач обретает все большую популярность. Одной из причин роста интереса к командному взаимодействию является стремительное изменение условий работы и учебного процесса. Возникает большое количество задач, которые не имеют однозначного решения, требуют нестандартного подхода, находятся на передовой социального или технологического развития. Такие задачи может решить только специально сформированная группа людей, команда «нужна именно для решения нетипичных творческих, сложных проблем и задач» $[1$, с. 766].

T. A. O'Neill, E. Salas, делая обзор современных исследований команд, отмечают, что современные научные и бизнес-задачи требуют совместной работы людей и организаций, и команды необходимы для достижения сложных, масштабных целей [2]. И если для команд коммерческих организаций актуальны, прежде всего, вопросы оптимизации деятельности и максимизации прибыли, то для команд, работающих в сферах спасения людей или устранения последствий стихийных бедствий, вопросы слаженности работы приобретают гораздо большее значение. V. Hagemann, A. Kluge называют команды, работающие в сложных условиях, командами высокой ответственности [3], и указывают, что промахи таких команд, если они не выявлены и не проработаны внутри команды, могут иметь серьезные последствия для людей и окружающей среды.

Возникает вопрос поиска некоторых базовых оснований командного взаимодействия, целенаправленное воздействие на которые может и повысить эффективность, и помочь в предотвращении критичных ошибок, и при этом создать комфортные психологические условия для участников команд. Одним из таких оснований является смысловая сфера команды, в которой происходит смысловая коммуникация и осуществляется динамика межличностных смыслов, возникает общее понимание командой характера своего взаимодействия и своей деятельности.

Целью исследования является рассмотрение смысловых процессов, протекающих в командном взаимодействии, и смысловых явлений, которые являются факторами, способствующими или препятствующими смысловым процессам. 
Новизна исследования обусловлена, с одной стороны, недостаточным количеством работ в рамках управленческого и социально-психологического подходов, затрагивающих смысловую сторону командного взаимодействия, с другой стороны, малым количеством исследований в рамках теории смысла, предметом которых является смысловое взаимодействие в команде.

Данная статья направлена на изучение возможности применения положений теории самоорганизации совместной мыслительной деятельности и психологии смысла к исследованию команд.

\section{Теоретическое обоснование}

Команда представляет собой сложный, многоплановый объект исследования, который рассматривается в рамках различных наук и направлений.

Понятие о команде как специально организованной группе людей, осуществляющей рабочую деятельность, впервые сформировалось в менеджменте, однако на сегодняшний день уже существует значительное количество психологических исследований. Среди зарубежных исследователей команд можно выделить таких наиболее цитируемых ученых, как Дж. Катценбах и Д. Смит, К. Б. Миллер, М. Геллерт и К. Новак, Р. Хакман, С. Танненбаум, Б. Такмен, М. Белбин; среди отечественных авторов можно отметить работы Т. Ю. Базарова, Ю. М. Жукова.

В зависимости от того, в каком из направлений рассматривается феномен команды, выделяются разные аспекты. Анализ различных определений команды показывает, что существуют, по крайней мере, два плана, в которых можно рассматривать командные характеристики. Первый план затрагивает внутреннее содержание, или сущностный аспект, второй план отражает внешние черты, наблюдаемые со стороны [1, 4]. В первом случае характеристики команды «описывают природу отношений участников, например, взаимную ответственность, чувство принадлежности к группе, координацию усилий, разделяемые ценности и цели» [4, с. 160]. К внешним характеристикам команды относятся: особый статус в организации, равный статус участников при принятии решений, возможность регулярных контактов участников и др. [1]. Можно сказать, что внутренний план затрагивает индивидуально-психологические особенности участников команды и социально-психологические условия, в которых происходит взаимодействие в команде; второй же план - это характеристики команды с точки зрения менеджмента, это ответы на вопросы о том, как формально устроена команда, какое место в организации она занимает.

Эти два плана отражают двоякую природу команды: с одной стороны команда представляет собой малую группу, в которой происходят различные социально-психологические процессы, с другой стороны, команда - это всегда специально организованное взаимодействие людей, имеющее определенные 


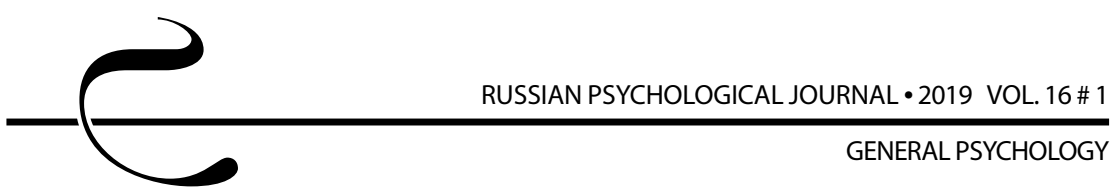

рамки, например срок существования команды может быть ограничен решением одной задачи.

Данная дихотомия выражается и в двух различных подходах к изучению команды: управленческом и социально-психологическом, изучающих различные характеристики командного взаимодействия. В рамках этих подходов накоплено большое количество данных о различных командных процессах.

При этом еще одна плоскость существования команды редко затрагивается в современных исследованиях команд в менеджменте и социальной психологии, а именно вопросы совместной мыслительной деятельности участников команды и динамики межличностных смыслов. В отечественной науке накоплен значительный опыт исследования смысловых явлений и смысловой динамики в рамках групповой (коллективной) и совместной деятельности. В данной работе мы опираемся на: исследования целеполагания и общего смыслового фонда в совместной мыслительной деятельности С. М. Джакупова [5]; разработанные Д. А. Леонтьевым представления о межличностных и внеличностных формах смысла, смысловой координации в совместной деятельности [6]; теорию самоорганизации совместной мыслительной деятельности А. К. Белоусовой [7]; разработку технологий направленной и опосредованной трансляции смыслов И. В. Абакумовой [8]; представления о смысловой коммуникации Л. Ц. Кагермазовой [9]. Однако применение результатов вышеперечисленных исследований для осуществления исследовательской и затем практической психологической работы с командами на сегодняшний день затруднено. Связано это с тем, что данные исследования проводились в различных сферах жизнедеятельности, напрямую не связанных с командами: например, теории смысловой коммуникации и направленной и опосредованной трансляции смыслов разработаны в рамках сферы образования и отражают аспекты смыслового взаимодействия педагога и учащихся.

\section{Результаты и их обсуждение}

Следуя методологии изучения смысла Д. А. Леонтьева [6], под смысловыми процессами в команде мы понимаем процессы возникновения и изменения смысловых образований, прежде всего межличностных и общих смыслов, в ходе осуществления командной деятельности. Смысловыми явлениями в команде мы называем отдельные смысловые феномены, возникающие в процессе командного взаимодействия.

Рассмотрим смысловые процессы и явления, имеющие наибольшее значение для исследования командного взаимодействия: смыслопередачу и формирование общих новообразований, особенности и факторы смысловой коммуникации, а также сплоченность как отражение протекания смысловых процессов в команде. 


\section{Смыслопередача и формирование общих новообразований}

В рамках изучения совместной мыслительной деятельности [7] был рассмотрен ряд тем, имеющих важное значение для исследования командного взаимодействия: совокупный субъект совместной мыслительной деятельности, формирование общих новообразований, самоорганизация совместной мыслительной деятельности, функциональная организация совместной мыслительной деятельности.

Важнейшим процессом, обеспечивающим протекание совместной мыслительной деятельности, является, по мнению А. К. Белоусовой, смыслопередача.

Смыслопередача представляет собой «процесс передачи партнеру открывшегося одному из участников смысла предмета, выраженного в значениях (или других формах презентации человеку - эмоционально, невербально и др.), который влияет на структурирование индивидуальной и совместной мыслительной деятельности, жизненный мир участников» [7, с. 193]. А. К. Белоусова подчеркивает, что «в совместной мыслительной деятельности смыслопередача выполняет системообразующую, генеративную и коммуникативную (передаточную) функции, инициируя формирование совмещенной психологической системы, а вместе с ней новых общих психологических ситуаций и общих участков жизненного мира участников, генерируя индивидуальные новообразования и передавая участникам особенности ценностно-смысловых отношений содержания их сознания» [10, с. 226].

При этом в ходе смыслопередачи осуществляется не только передача, обмен смыслами, но и перестройка ценностно-смысловой сферы участников команды: «в ходе совместной мыслительной деятельности посредством смыслопередачи происходит раскрытие смыслов партнеров, определяя тем самым становление их общих смыслов. Всё это приводит к изменениям смыслового сознания, или смысловых полей многомерного мира испытуемых» [11, с. 121].

Итак, смыслопередача является ключевым процессом в совместной мыслительной деятельности, который способствует появлению качественно новых, общих новообразований. Проявляется это следующим образом. В условиях совместной мыслительной деятельности на индивидуальные новообразования участников, а это, прежде всего, смыслы, цели, мотивы, оценки, оказывают существенное влияние новообразования других участников. Это инициирует «появление качественно новых новообразований, не сводимых к особенностям индивидуальных новообразований каждого участника и имеющих совмещенный (общий) характер» [7, с. 83-84].

Главным общим новоообразованием в совместной мыслительной деятельности является общая психологическая ситуация. Именно появление общей психологической ситуации ведет к становлению совместной мыслительной 
деятельности: «общая психологическая ситуация служит показателем и основанием для совместной мыслительной деятельности» [7, с. 86].

Общая психологическая ситуация представляет собой некую «площадку», на которой происходит формирование других общих новообразований, это «область, в которой смыслы и ценности предметов одного участника соответствуют смыслам и ценностям другого» [7, с. 87].

Среди образующихся в совместной мыслительной деятельности общих новообразований важнейшее место занимают общие смыслы. Изначально смысл, т. е. роль и место предмета в жизненном мире человека, является индивидуальным образованием. Однако, вступая во взаимодействие, люди начинают предъявлять и передавать друг другу смыслы, «психологические качества предметов» [12, с. 25], которые выражаются в значениях или невербальных и эмоциональных образах, постепенно формируются общие смыслы предметов. Через формирование общей психологической ситуации, образование общих смыслов создаются и другие общие новообразования: цели, мотивы, оценки.

Сформированность общих новообразований отражает стадию, на которой находится совместная деятельность участников команды.

С. М. Джакупов предлагает следующие стадии формирования совместной мыслительной деятельности: «индивидуальные практические действия - совместная практическая деятельность - псевдосовместная мыслительная деятельность - совместная мыслительная деятельность - пседвоиндивидуальная мыслительная деятельность» [13, с. 182]. На стадии псевдосовместной мыслительной деятельности, которую С. М. Джакупов называет «первичной, примитивной стадией развития совместной мыслительной деятельности» [5, с. 2], имеет место только внешняя цель, а общие смыслы и общие мотивы еще не сформированы. И только с образованием общего мотива и, в достаточно большой степени, совпадением индивидуальных смыслов происходит переход к совместной мыслительной деятельности.

Д. А. Леонтьев, рассматривая факторы становления совместной деятельности, указывает на необходимость формирования общего мотива: «по своей структуре совместная деятельность аналогична индивидуальной; отличие же заключается в том, что в своих звеньях она распределена между двумя и более субъектами, у которых в этот момент нет никакой индивидуальной деятельности, отличной от деятельности, совместно распределенной между ними, со-субъектами они выступают. Таким образом, эта деятельность имеет не только общую для ее со-субъектов операционную, но и общую мотивационную смысловую структуру» [6, с. 397-398].

Таким образом, для перехода на стадию совместной мыслительной деятельности участникам команды необходимо как минимум сформировать общие смыслы и мотивы деятельности. 
C. Aubé с соавторами называют степень сформированности у участников команды общего представления о работе, которую они должны выполнить, одним из краеугольных камней результативности команды в организации. Общее представление имеет сложное содержание, в него включаются факты, причины происходящих событий, взгляды на будущее команды и т. д.: наличие общих умственных представлений позволяет членам команды интерпретировать имеющуюся информацию похожим образом (что происходит?), схожим образом объяснять события (почему это происходит?) и иметь общие ожидания о предстоящих событиях (что будет дальше?) [14]. Важно отметить, что авторы анализируют феноменологическую сторону общего представления о работе, в отличие от исследований, где затрагиваются объективные аспекты общего понимания работы. С. Аubé с соавторами указывают, что объективные аспекты мысленных представлений необходимы, но недостаточны для стимулирования оптимальной работы команды.

Таким образом, выделяются два аспекта общего понимания: феноменологический (что составляет содержание общего понимания) и объективный (как в работе проявляется общее понимание). Данный феноменологический аспект согласуется с концепцией образования общих новообразований, в первую очередь смыслов. Наличие общих смыслов, целей, оценок, мотивов как раз и позволяет участникам команды, находящимся в общей психологической ситуации, интерпретировать информацию и иметь согласованность относительно причин происходящих с командой событий. Это подтверждает тезис о том, что в совместной деятельности, в особенности в совместной деятельности команды, важна не только общая операционная структура (общее понимание того, «как нам это делать»), но и мотивационная смысловая структура («чем является для нас то, что мы делаем, в контексте чего мы это делаем и для чего»).

\section{Смысловая коммуникация}

Общие, межличностные смыслы, возникающие в процессе смыслопередачи, являются базой для формирования общего, совместного смыслового пространства. В исследовании С. М. Джакупова используются схожие понятия смыслового поля и общего смыслового фонда. По его мнению, совместная деятельность «представлена с предметной стороны общим объектом деятельности, а с идеальной - смысловым полем, образованным в результате частичного совпадения смысловых образований» [5, с. 2].

Исследуя феномен «осознанного общего понимания» («perceived shared understanding») на выборке из 101 команды, С. Aubé с соавторами приходят к выводу, что такого рода общее понимание может способствовать гармоничным межличностным отношениям в команде и стимулировать участников 


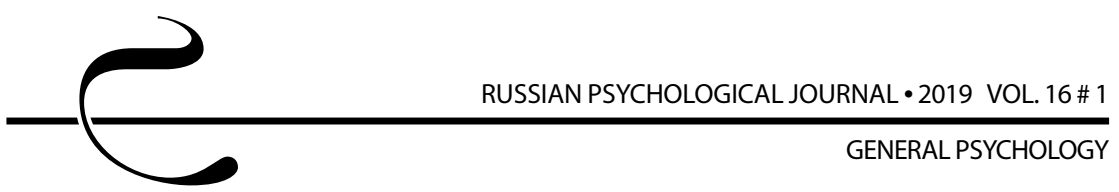

продолжать совместную работу [15]. Авторы указывают, что осознанное общее понимание относится к степени, в которой члены команды верят, что они согласны друг с другом относительно работы, которая должна быть выполнена в команде. Их исследование сосредоточено на мысли о том, что члены команды имеют одинаковое понимание результатов, которые должны быть достигнуты (цели, приоритеты, сроки), и средств их достижения (методов работы, стратегий, распределения ролей и обязанностей) [15]. Метафорично авторы называют такое состояние командного взаимодействия «нахождением на одной странице» («оn the same page»).

В современных зарубежных исследованиях подчеркивается важность развития в командах разного рода общего понимания и его связь с коммуникациями в команде. Ph. Cash, E. Dekoninck, S. Ahmed-Kristensen отмечают, что общее понимание является ключевым показателем эффективности коммуникации в распределенных командах, и на основе экспериментальных данных показывают значимость общего понимания и поддержки групповой коммуникации в распределенных группах инженерного проектирования [16]. Особую актуальность вопросы общего понимания приобретают для виртуальных команд, участники которых географически разделены, и состав таких команд часто отличается культурным и функциональным разнообразием [17]. В связи с развитием технологий и мобильности рабочей силы количество команд, участники которых не имеют возможности встречаться непосредственно, будет возрастать. Это побуждает подробнее исследовать вопросы того, как организовать командное взаимодействие в ситуации разнородных групп.

С позиции смыслового подхода осознанное общее понимание может быть понято как проявление сформировавшегося в команде общего смыслового фонда, а одинаковое понимание результатов и средств их достижения отражает успешное формирование общих новообразований. При этом возникает важный вопрос о путях образования общего смыслового фонда и осознанного общего понимания в команде.

Общий смысловой фонд формируется постепенно в совместной мыслительной деятельности и в ходе общения участников. Д. Ф. Даутов, Е. А. Суроедова уточняют, как это осуществляется: «в процессе формирования общего смыслового фонда происходит обмен смысловыми образованиями, обмен информацией о целях, задачах и способах деятельности, обмен оценками и отношениями к деятельности, которая передается с помощью эмоционального канала» $[18$, с. 57-58].

Общение участников команды может происходить на различных по глубине уровнях: от простой передачи информации до глубинного ценностно-смыслового межличностного общения. При этом в общении на смысловом уровне Д. Ф. Даутов, Е. А. Суроедова выделяют, в свою очередь, два уровня: 
1. Смыслопередача предстает как коммуникация и понимание между участниками. Участники могут понимать, принимать, интерпретировать смыслы других участников.

2. На более глубоком и личностно значимом уровне смыслопередача происходит «в диалоге, взаимодействии, в совместной деятельности, когда происходит трансформация ценностно-смысловой сферы личности, ее установок, целей, мотивов» [18, с. 58].

Второй уровень может быть описан термином «смысловая коммуникация», введенным Л. Ц. Кагермазовой. По ее мнению, смысловая коммуникация - это ценностное взаимодействие, которое является «процессуальной составляющей группового смыслообразующего контекста, ориентированной прежде всего на развитие, прежде всего смысловой, ценностной сферы» $[9$, с. 56]. Технологией, позволяющей реализовать смысловую коммуникацию, является диалог. Понятие о диалоге как технологии направленной трансляции смыслов сегодня активно исследуется в контексте практики учебного процесса. И. В. Абакумова, Л. Ц. Кагермазова, П. Н. Ермаков выделяют межличностный диалог как «средство инициирования смыслообразования обучаемых в процессе обучения, поскольку именно диалог и выступает катализатором смыслообразования, запускающим “поток сознания", переход от потенциального к актуализированному и определяющим уровень смысловой насыщенности учебного контекста и приоритеты его ценностно-смысловых центраций» [8, с. 103]. В зарубежных работах рассматривается схожая технология поддержки активности участников команд, суть которой состоит в задавании участниками друг другу вопросов, что является ключевым фактором формирования общего понимания [16].

М. А. Фризен рассматривает три смысловые центрации сознания, которые определяют способ осмысления мира человеком: «через личные интересы (эгоцентрация), через нормы и ценности референтной группы (группоцентрация), через ориентацию на благо других людей и человечество в целом (просоциальная центрация)» [19, с. 11]. При этом низкий уровень развития смысловой сферы характеризуется жесткостью, ригидностью центраций, а высокий - гибкостью центраций; доминирующая центрация может дополняться элементами другой центрации.

Сближение участников совместной мыслительной деятельности посредством диалога можно рассматривать как показатель успешной смыслопередачи, а возрастание гибкости центраций участников - как показатель развития их смысловой сферы и общего смыслового поля.

Среди смысловых явлений, возникающих в смысловой коммуникации, стоит выделить смысловой резонанс и смысловой диссонанс.

Понятие смыслового резонанса было введено Е. Л. Доценко при изучении становления совместных смысловых систем в процессе общения. 


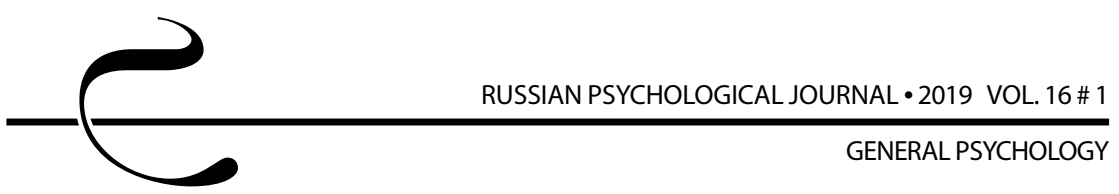

Смысловым резонансом автор называет обоюдный поиск участниками общения сходства их семантических структур. По мнению Е. Л. Доценко, появление смыслового резонанса происходит следующим образом. Один из партнеров, желая увеличить степень определенности во взаимоотношениях, привносит свое содержание в совместное семантическое поле. Другой партнер ищет сходство и, если находит, делает встречный шаг вкладывает свое содержание. Далее цикл повторяется, это обеспечивает гибкий баланс между психологическими системами партнеров. «Субъективно момент совпадения переживается как своеобразный душевный резонанс. Рабочим инструментом взаимопонимания становится создаваемая партнерами по общению общая семантическая (смысловая) структура, которая выступает специализированным переводчиком (интерпретатором) с одного субъективного языка на другой» [20, с. 180]. Таким образом, в результате направленной друг на друга активности участников общения достигается глубокое взаимопонимание на ценностно-смысловом уровне, происходящее на фоне образующегося общего смыслового поля.

Смысловой диссонанс представляет собой противоположное явление. Смысловой диссонанс означает несовпадение смыслов участников взаимодействия, ведет к нарушению смысловой коммуникации. По И. В. Абакумовой, М. В. Годунову, «смысловой диссонанс - возникает в случае несогласованности экзистенциальных систем субъектов при коммуникации различного рода. Данное несовпадение смыслов означает сбой их регулятивной функции при "опредмечивании" и "распредмечивании" деятельности, обеспечивающей приемлемое качество взаимодействий» [21, с. 5-6]. Авторы выделяют диссонанс единичных смыслов и диссонанс общих смыслов (в ситуации трансляции межличностных смыслов).

Относительно командного взаимодействия изучение смысловой коммуникации открывает путь к исследованию глубинных смысловых процессов в команде. Общий смысловой фонд выступает результатом, а затем регулятором смыслового взаимодействия, смысловой диалог и достижение смыслового резонанса - конкретными механизмами, обеспечивающими ценностно-смысловой контакт, смысловой диссонанс выступает в качестве смыслового психологического барьера для осуществления деятельности.

Одной из важных характеристик коммуникации в команде является рефлексивность. E. Hedman-Phillips, J. K. Barge, понимая рефлексивность как степень, в которой члены команды открыто размышляют о групповых целях, стратегиях и процессах, указывают, что исследования подтверждают положительную связь с эффективностью, производительностью команды, наличием инноваций, с облегчением процесса принятия решений; рефлексивность предотвращает сбои при обработке информации в рамках групповых процессов [22]. 
Условием рефлексии, глубокого анализа своей деятельности командой выступает образование общего смыслового поля, в котором происходит смысловой диалог. В этом случае смыслопередача должна происходить на глубоком, личностно-значимом уровне, чтобы обеспечить не просто понимание, а инициирование изменений в ценностно-смысловой сфере участников для изменения их поведения и отношения к работе и командному взаимодействию.

Представление о том, что коммуникация в команде должна быть направлена на формирование общего понимания, присутствует в современных зарубежных работах по изучению командного взаимодействия. C. Aubé с соавторами, давая практические рекомендации руководителям проектов, подчеркивают, что они должны помочь членам своей команды выработать общее понимание работы. Для этого руководители проектов должны не только способствовать хорошей коммуникации между членами на регулярной основе, но и организовывать семинары по стратегическому планированию, тренинги по командообразованию, упражнения на командную рефлексию [14]. Эти мероприятия, по сути, являются внешней формой, в которую может быть облечена смысловая коммуникация, и действиями по формированию общего смыслового фонда.

Развивать и поддерживать смысловую коммуникацию в команде очень важно, установление такой коммуникации отражает высокое качество взаимодействия участников. Как установили Sh. L. Marlow c соавторами в метаанализе, посвященном исследованию коммуникации в команде, качество связи имеет значительно более сильную связь с работой команды, чем частота общения [23].

\section{Сплоченность команды как отражение протекания смысловых} прочессов

Сплоченность группы в зарубежной психологии и коллектива в отечественной является давним предметом изучения. В отечественной психологии значительный вклад в изучение сплоченности внесли такие исследователи, как А. В. Петровский, А. И. Донцов, А. Л. Журавлев. Сплоченность рассматривается как одна из важнейших характеристик группы, связанная с другими групповыми явлениями и характеристиками: эффективностью, особенностями организации совместной деятельности, мотивационной сферой, уровнем развития группы [24].

При этом взгляды на природу сплоченности отличаются большим разнообразием. В традиционном отечественном стратометрическом подходе к исследованию коллективов сплоченность понималась как ценностно-ориентационное единство. А. В. Сидоренков и А. Л. Мондрус выделяют ряд ключевых аспектов сплоченности, которые рассматриваются в разных подходах: 
аттракция как межличностная привлекательность членов группы или группы в целом для ее членов; социально-перцептивные процессы как плоскость межличностных связей или связей членов с группой; символическая активность как усвоение профессионального языка, ролей, ритуалов [25]; также исследованы эмоциональные детерминанты сплоченности [26]. Авторы предлагают различать два вида сплоченности: предметно-деятельностную, которая относится к совместной деятельности, и социально-психологическую, которая относится к сфере общения. Это соотносится с теорией групп и коллективов А. В. Петровского, в которой сплоченность относилась к межличностным связям, опосредованным содержанием совместной деятельности, в отличие от межличностных связей возникающим вне совместной деятельности [27].

Вышеописанные представления о сплоченности групп и коллективов справедливы и для команд, т. к. команда является специфическим видом группы и так же, как и коллектив, осуществляет целенаправленную деятельность. При этом, поскольку в основе командного взаимодействия лежит совместная мыслительная деятельность, наибольшее значение для команды приобретает сплоченность, опосредованная содержанием совместной деятельности, предметно-деятельностная сплоченность.

В смысловом подходе к командному взаимодействию основанием сплоченности могут быть названы общие новообразования, а степень их сформированности - индикатором уровня сплоченности. Это согласуется с классическими отечественными исследованиями. А. И. Донцов рассматривал сплоченность группы как схожесть ценностных представлений о цели общей деятельности и их актуализации в практике [28]. Ценностные представления участников команды, рассмотренные в рамках концепции совместной мыслительной деятельности, - это, по сути, смыслы совместной деятельности. Схожесть смыслов возникает в случае успешного осуществления процесса смыслопередачи, в условиях, когда между участниками команды установлена смысловая коммуникация. Таким образом, сплоченность команды можно определить как готовность участников к смыслопередаче, смыслопостижению, к ценностному и смысловому взаимодействию.

Сплоченность команды, прежде всего предметно-деятельностная, выступает показателем развития совместной мыслительной деятельности. Она означает, что участники команды достигли высокой степени взаимопонимания за счет образования значительных совмещенных участков их жизненных миров. Понимание сплоченности как определенного уровня развития смысловой сферы команды открывает возможность применения новых методов ее достижения: диалога, смыслового резонанса, сближения по смысловым центрациям. В то же время, смысловой диссонанс может рассматриваться как препятствие к достижению сплоченности команды. 
В этом контексте сплоченность команды можно рассматривать как предпосылку успешной реализации распределенного или совместного лидерства в командах, когда не один человек является лидером, а остальные ведомыми, но все участники принимают участие в принятии решений. По мнению J. B. Carson, P. E. Tesluk, J. A. Marrone, совместное лидерство является критическим фактором, который может улучшить производительность команды, но для его появления и развития необходимо уделять внимание таким аспектам командной работы, как общая цель, социальная поддержка участниками команды друг друга и «голос» (активное участие каждого члена команды) [29]. С.-H. Huang после исследования 35 рабочих команд обнаружил значительное положительное влияние совместного лидерства на обучение команды [30]. Именно сплоченность команды как отражение успеха смысловой коммуникации и высокого уровня динамики межличностных смыслов позволяет участникам чувствовать себя уверенно в ситуации командного взаимодействия, свободно себя проявлять и включаться в общее управление командными процессами.

\section{Заключение}

Команда представляет собой многомерный объект исследования, находящийся на стыке нескольких дисциплин, каждая из которых освещает одну из сторон команды. В социальной психологии рассматриваются, прежде всего, социально-психологические аспекты межличностного взаимодействия участников команды, в менеджменте в центре внимания находятся условия наиболее эффективной организации командной работы. Еще одной важной стороной командного взаимодействия являются смысловые процессы и явления, - их изучение можно объединить в рамках смыслового подхода.

Анализ литературы по данной теме позволяет сделать вывод о том, что процессы смыслопередачи и формирования общих новообразований имеют ключевое значение для командного взаимодействия, т. к. они являются основой для становления совместной мыслительной деятельности. Смысловая коммуникация является особым видом коммуникации, ее наличие и поддержание между участниками команды способствует созданию общего смыслового фонда - важнейшего общего психологического образования. Технологией, которая активизирует и инициирует процесс смысловой коммуникации, является диалог между участниками команды. Становление смысловой коммуникации осуществляется через достижение участниками смыслового резонанса в попытках установить взаимопонимание через соотнесение своего содержания с содержанием партнера. Несовпадение смыслов переживается участниками команды как смысловой диссонанс и представляется не только как барьер для смысловой коммуникации, но и для всей командной деятельности в целом. Индикаторами развития смысловой сферы участников и смыслового поля команды являются 


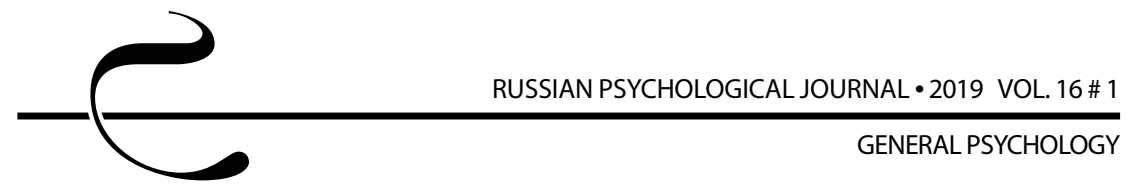

феномены сближения по смысловым центрациям и высокий уровень сплоченности, понимаемый как готовность к смысловому взаимодействию.

Таким образом, смысловой подход является дополнением к существующим исследованиям команд; в то же время он позволяет раскрыть специфические смысловые аспекты командного взаимодействия. Исследование смысловых процессов и явлений в команде представляется актуальным и перспективным направлением, при этом для более полного понимания смысловой динамики конкретно в командном взаимодействии требуется дальнейшее теоретическое и методологическое развитие данной темы, а эмпирические исследования смысловых аспектов командного взаимодействия могли бы уточнить теоретические модели.

\section{Литература}

1. Шмаков Б. В., Фомин М. А. Уточнение содержания понятия «команда» в концепции управления проектом // Наука ЮУрГУ: материалы 67-й научной конференции. Секции экономики, управления и права. Челябинск: Издательский центр ЮУрГУ, 2015. С. 763-770.

2. O'Neill T.A., Salas E. Creating high performance teamwork in organizations // Human Resource Management Review. 2018. Vol. 28, Issue 4. P. 325-331. DOI: 10.1016/j.hrmr.2017.09.001

3. Hagemann V., Kluge A. Complex Problem Solving in Teams: The Impact of Collective Orientation on Team Process Demands // Frontiers in Psychology. 2017. Vol. 8, Article 1730. DOI: 10.3389/fpsyg.2017.01730

4. Чанько А.Д. Командообразование в современных организациях: междисциплинарный синтез психологии и менеджмента // Вестник Санкт-Петербургского университета. Серия 8. Менеджмент. 2007. № 2. С. 157-177.

5. Джакупов С. М. Целеобразование в совместной мыслительной деятельности: автореф. дисс. ... канд. психол. наук. Москва, 1985. 22 с.

6. Леонтьев Д. А. Психология смысла: природа, строение и динамика смысловой реальности. 3-е изд., доп. М.: Смысл, 2007. 511 с.

7. Белоусова А. К. Самоорганизация совместной мыслительной деятельности. Ростов-на-Дону: Изд-во РГПУ, 2002. 360 с.

8. Абакумова И. В., Кагермазова Л. Ц., Ермаков П. Н. Технологии направленной трансляции смыслов в практике учебного процесса: монография. М.: КРЕДО, 2016. $234 \mathrm{c}$.

9. Кагермазова Л. Ц. Смысловые коммуникации в учебном процессе: теория и технологии направленной трансляции смыслов в обучении: автореферат дисс. ... д-ра психол. наук. Ростов-на-Дону, 2009. 66 с.

10. Белоусова А. К. Смыслопередача в совместной мыслительной деятельности // Категория смысла в философии, психологии, психотерапии 
и в общественной жизни: Материалы Всероссийской психологической конференции с международным участием (Ростов-на-Дону, 23-26 апреля 2014 г.). М.: КРЕДО, 2014. С. 225-226.

11. Даутов Д. Ф., Белоусова А. К. Взаимовлияние партнеров в совместной мыслительной деятельности в практике обучения // Известия Южного федерального университета. Педагогические науки. 2009. № 9. С. 117-127.

12. Белоусова А. К. Смыслопередача и её роль в образовании совмещённой психологической системы // Сибирский психологический журнал. 2004. № 20. С. 22-28.

13. Джакупов С. М. Развитие смысловой теории мышления в концепции совместно-диалогической познавательной деятельности // Вестник Московского университета. Серия 14: Психология. 2008. № 2. С. 180-188.

14. Aubé C., Rousseau V., Brunelle E. et al. The relevance of being "on the same page" to succeed as a project team: A moderated mediation model // Motivation and Emotion. 2018. Vol. 42, Issue 6. P. 804-815. DOI: 10.1007/s11031-018-9706-2

15. Aubé C., Rousseau V., Tremblay S. Perceived shared understanding in teams: The motivational effect of being 'on the same page'// British Journal of Psychology. 2015. Vol. 106, Issue 3. P. 468-486. DOI: $10.1111 /$ bjop.12099

16. Cash P., DekoninckE. A., \& Ahmed-Kristensen S. Supporting the development of shared understanding in distributed design teams // Journal of Engineering Design. 2017.Vol. 28, Issue 3.P. 147-170.DOI: 10.1080/09544828.2016.1274719

17. PaulS., He F., Dennis A. R. Group Atmosphere, Shared Understanding, and Team Conflict in Short Duration Virtual Teams // Proceedings of the 51stHawaii International Conference on System Sciences. Honolulu, 2018. P. 361-370. DOI: $10125 / 49935$

18. Даутов Д. Ф., Суроедова Е. А. Феномены совместной мыслительной деятельности. Ростов-на-Дону: Изд-во ДГТУ, 2012. 168 с.

19. Фризен М. А. Особенности развития смысловой сферы подростков: автореферат дисс. ... канд. психол. наук. Хабаровск, 2005. 23 с.

20. Доценко Е. Л. Межличностное общение: семантика и механизмы. Тюмень: ТОГИРРО, 1998. 202 с.

21. Абакумова И. В., Годунов М. В. Смысловой диссонанс и альтернативное оценивание свойств личности // Национальное здоровье. 2017. № 1-2.С. 137-150.

22. Hedman-Phillips E., Kevin Barge J. Facilitating Team Reflexivity About Communication // Small Group Research. 2017. Vol. 48, Issue 3. P. 255-287. DOI: $10.1177 / 1046496416684962$

23. Marlow Sh. L., Lacerenza C. N., Paoletti J., et al. Does team communication represent a one-size-fits-all approach?: A meta-analysis of team communication and performance // Organizational Behavior and Human Decision Processes. 2018. Vol. 144. P. 145-170. DOI: $10.1016 /$ j.obhdp.2017.08.001 
24. Психология малой группы: ретроспективный научно-вспомогательный указатель отечественных трудов / под ред. А. В. Сидоренкова. М.: КРЕДО, 2014. 268 с.

25. Сидоренков А. В., Мондрус А. Л. Эмпирическое обоснование модели групповой сплоченности // Психологический журнал. 2012. Т. 33, № 2. С. 45-58.

26. Сысоева А. И. Эмоциональные детерминанты сплоченности малых групп // Теория и практика общественного развития. 2014. №20. С. 204-207.

27. Немов Р. С., Шестаков А. Г. Сплоченность как фактор групповой эффективности // Вопросы психологии. 1981. № 3. С. 113-119.

28. Донцов А. И. Проблемы групповой сплоченности. М.: Изд-во МГУ, 1979. $126 \mathrm{c}$.

29. Carson J. B., Tesluk P. E., Marrone J. A. Shared Leadership in Teams: An Investigation of Antecedent Conditions and Performance // Academy of Management Journal. 2007. Vol. 50, № 5. P. 1217-1234. DOI: 10.5465/amj.2007.20159921

30. Huang C.-H. Shared Leadership and Team Learning: Roles of Knowledge Sharing and Team Characteristics // The Journal of International Management Studies. 2013. Vol. 8, № 1. P. 124-133.

\section{References}

1. Shmakov B. V., Fomin M. A. Utochnenie soderzhaniya ponyatiya «komanda» $v$ kontseptsii upravleniya proektom [Clarification of the concept of team in the theory of project management]. Nauka YuUrGU:materialy 67-inauchnoi konferentsii. Sektsii ekonomiki, upravleniya i prava [Nauka SUSU: Proceedings of the 67th Theoretical Conference: Sections in economics, management and law]. Chelyabinsk, SUSU Publ., 2015, pp. 763-770.

2. O'Neill T. A., Salas E. Creating high performance teamwork in organizations. Human Resource Management Review, 2018, V. 28, Issue 4, pp. 325-331. DOI: 10.1016/j.hrmr.2017.09.001

3. Hagemann V., Kluge A. Complex problem solving in teams: The impact of collective orientation on team process demands. Frontiers in Psychology, 2017, V. 8, Article 1730. DOI: 10.3389/fpsyg.2017.01730

4. Chanko A. D. Team building in modern organizations: An interdisciplinary synthesis of psychology and management. Vestnik Sankt-Peterburgskogo universiteta. Seriya 8. Menedzhment - Bulletin of St. Petersburg University: Series 8: Management, 2007, no. 2, pp. 157-177 (in Russian).

5. Dzhakupov S. M. Tseleobrazovanie v sovmestnoi myslitel'noi deyatel'nosti [Goal formation in joint mental activity]. Diss. Cand. Sci. (Psych.), 1985.

6. Leont'ev D. A. Psikhologiya smysla: priroda, stroenie i dinamika smyslovoi real'nosti [Psychology of meaning: Nature, structure, and dynamics of meaning reality]. Moscow, Smysl Publ., 2007. 511 p. 
7. Belousova A. K. Samoorganizatsiya sovmestnoi myslitel'noi deyatel'nosti [Selforganization of joint mental activity]. Rostov-on-Don, RSPU Publ., 2002.360 p.

8. Abakumova I. V., Kagermazova L. Ts., Ermakov P. N. Tekhnologii napravlennoi translyatsii smyslov $v$ praktike uchebnogo protsessa [Technologies of the directed translation of meanings in the educational process]. Moscow, Kredo Publ., 2016. 234 p.

9. Kagermazova L. Ts. Smyslovye kommunikatsii v uchebnom protsesse: teoriya i tekhnologii napravlennoi translyatsii smyslov v obuchenii [Meaning communications in the educational process: Theory and technologies of the directed translation of meanings in training]. Rostov-on-Don, 2009.66 p.

10. Belousova A. K. Smysloperedacha v sovmestnoi myslitel'noi deyatel'nosti [Meaning transmission in joint mental activity]. Kategoriya smysla v filosofii, psikhologii, psikhoterapii i v obshchestvennoi zhizni: Materialy Vserossiiskoi psikhologicheskoi konferentsii s mezhdunarodnym uchastiem [The category of meaning in philosophy, psychology, psychotherapy, and in public life: Proc. the all-Russian psychological conference with the international participation]. Rostov-on-Don, Kredo Publ., 23-26 April, 2014, pp. 225-226.

11. Dautov D. F., Belousova A. K. Mutual interaction of partners in joint mental activity in training. Izvestiya Yuzhnogo federal'nogo universiteta. Pedagogicheskie nauki - Proceedings of the Southern Federal University: Pedagogical Science, 2009, no. 9, pp. 117-127 (in Russian).

12. Belousova A. K. Meaning transmission and its role in the formation of a combined psychological system. Sibirskii psikhologicheskii zhurnal-Siberian Psychological Journal, 2004, no. 20, pp. 22-28 (in Russian).

13. Dzhakupov S. M. Development of the meaning theory of thinking in the concept of co-dialogical cognitive activity. Vestnik Moskovskogo universiteta. Seriya 14: Psikhologiya - Moscow University Psychology Bulletin, 2008, no. 2, pp. 180-188 (in Russian).

14. Aubé C., Rousseau V., Brunelle E. et al. The relevance of being "on the same page" to succeed as a project team: A moderated mediation model. Motivation and Emotion, 2018, V. 42, Issue 6, pp. 804-815. DOI: 10.1007/s11031-018-9706-2

15. Aubé C., Rousseau V., Tremblay S. Perceived shared understanding in teams: The motivational effect of being 'on the same page'. British Journal of Psychology, 2015, V. 106, Issue 3, pp. 468-486. DOI: 10.1111/bjop.12099

16. Cash P., Dekoninck E. A., \& Ahmed-Kristensen S. Supporting the development of shared understanding in distributed design teams. Journal of Engineering Design, 2017, V. 28, Issue 3, pp. 147-170. DOI: 10.1080/09544828.2016.1274719

17. Paul S., He F., Dennis A. R. Group atmosphere, shared understanding, and team conflict in short duration virtual teams. Proceedings of the 51stHawaii International Conference on System Sciences. Honolulu, 2018, pp. 361-370. DOI: 10125/49935 
18. Dautov D. F., Suroedova E. A. Fenomeny sovmestnoi myslitel'noi deyatel'nosti [Phenomena of joint mental activity]. Rostov-on-Don, DSTU Publ., 2012. 168 p.

19. Frizen M. A. Osobennosti razvitiya smyslovoi sfery podrostkov [Characteristics of the development of adolescents' meaning sphere]. Khabarovsk, 2005.

20. Dotsenko E. L. Mezhlichnostnoe obshchenie: semantika i mekhanizmy [Interpersonal communication: Semantics and mechanisms]. Tyumen, Togirro Publ., 1998. 202 p.

21. Abakumova I. V., Godunov M. V. Meaning dissonance and alternative assessment of personality traits. Natsional'noe zdorov'e - National Health, 2017, no. 1-2, pp. 137-150 (in Russian).

22. Hedman-Phillips E., Kevin Barge J. Facilitating team reflexivity about communication. Small Group Research, 2017, V. 48, Issue 3, pp. 255-287. DOI: $10.1177 / 1046496416684962$

23. Marlow Sh. L., Lacerenza C. N., Paoletti J., et al. Does team communication represent a one-size-fits-all approach?:A meta-analysis of team communication and performance. Organizational Behavior and Human Decision Processes, 2018, V. 144, pp. 145-170. DOI: 10.1016/j.obhdp.2017.08.001

24. Sidorenkov A. V. (ed.) Psikhologiya maloi gruppy: retrospektivnyi nauchnovspomogatel'nyi ukazatel' otechestvennykh trudov [The psychology of small groups: A retrospective research-accessory index of domestic works.]. Moscow, Credo Publ., 2014. 268 p.

25. Sidorenkov A. V., Mondrus A. L. Empirical foundation for the model of group cohesion. Psikhologicheskii zhurnal, 2012, V. 33, no. 2, pp. 45-58 (in Russian).

26. Sysoeva A. I. Emotional determinants of cohesion in small groups. Teoriya i praktika obshchestvennogo razvitiya - Theory and Practice of Social Development, 2014, no. 20, pp. 204-207 (in Russian).

27. Nemov R. S., Shestakov A. G. Cohesion as a factor of group efficiency. Voprosy psikhologii, 1981, no. 3, pp. 113-119 (in Russian).

28. Dontsov A. I. Problemy gruppovoi splochennosti [Problems of group cohesion]. Moscow, Moscow State University Publ., 1979. 126 p.

29. Carson J. B., Tesluk P. E., Marrone J. A. Shared leadership in teams: An investigation of antecedent conditions and performance. Academy of Management Journal, 2007, V. 50, no. 5, pp. 1217-1234. DOI: 10.5465/ amj.2007.20159921

30. Huang C.-H. Shared leadership and team learning: Roles of knowledge sharing and team characteristics. The Journal of International Management Studies, 2013, V. 8, no. 1, pp. 124-133. 